British Journal of Pharmacology and Toxicology 4(6): 256-261, 2013

DOI:10.19026/bjpt.4.5409

ISSN: 2044-2459; e-ISSN: 2044-2467

(C) 2013 Maxwell Scientific Publication Corp.

Submitted: August 24, $2013 \quad$ Accepted: September 03, $2013 \quad$ Published: December 25, 2013

\title{
Research Article Protective Effect of Penta-acetyl Geniposide on Acute Liver Injury Induced By D-galactosamine in Mice
}

\author{
${ }^{1}$ Hong Zhang, ${ }^{1,2}$ Tianlu Shi, ${ }^{1}$ Jing Wang, ${ }^{1}$ Rong Li and ${ }^{1}$ Wenjian Tang \\ ${ }^{1}$ School of Pharmacy, Anhui Medical University, Hefei, 230032, China ${ }^{2}$ Anhui Provincial Hospital, Anhui \\ Medical University, Hefei 230001, China
}

\begin{abstract}
Penta-acetyl geniposide ((Ac) $\left.)_{5} \mathrm{GP}\right)$, an herbal derivative prepared from Gardenia Fructus geniposide, decreased the DNA damage and hepatocarcinogenesis induced by aflatoxin $\mathrm{B}_{1}\left(\mathrm{AFB}_{1}\right)$. The present study was carried out to further evaluate the protective effect of $(\mathrm{Ac})_{5} \mathrm{GP}$ on liver injury induced by D-galactosamine (DGalN). D-GalN (400 mg/kg) was given to mice by intraperitoneal injection, while (Ac) ${ }_{5} \mathrm{GP}$ were orally administered by gastric gavage. Spectrophotometrical method was used to measure activities of aspartate aminotransferase (AST), alanine aminotransferase (ALT) in serum and superoxide dismutase (SOD), glutathione peroxidase (GSH-Px), malondialdehyde (MDA) in hepatic tissue. Hepatic histological structure was observed under light microscopy. The features of acute liver injury were observed in D-GalN-treated mice. (Ac) ${ }_{5} \mathrm{GP}$, similar to silymarin, decreased the elevated serum levels of ALT, AST and MDA and increased the reduced activities of SOD and GSH-Px induced by D-GalN. (Ac) ${ }_{5} \mathrm{GP}$ was also showed to be more effective than GP in reversing these abnormal changes and the levels of $(\mathrm{Ac})_{5} \mathrm{GP}$ on MDA and SOD showed a dose-effect relationship. These biochemical observations were also supplemented by histopathological observations of the liver sections. It was concluded from the results that (Ac) ${ }_{5} \mathrm{GP}$ can produce protective effect on acute liver injury induced by D-GalN via an antioxidative mechanism. Therefore, (Ac) $)_{5}$ GP may be developed as an efficient hepato-protective agent.
\end{abstract}

Keywords: Antioxidative effect, D-galactosamine, gardenia, liver injury, penta-acetyl geniposide

\section{INTRODUCTION}

Gardenia, the fruit of Gardenia jasminoides Ellis, has been widely used to treat liver and gall bladder disorders, such as hepatitis, acute jaundice and inflammation, in Chinese medicine for many years (Peng et al., 2004). Geniposide (GP), a main iridoid glycoside component isolated from Gardenia Fructus, has been shown to possess diverse pharmacological activities, such as anti-inflammatory (Liu et al., 2010; Yang et al., 2012), anti-oxidative (Liu et al., 2007, 2009; Ma et al., 2011), anti-tumor (Cao et al., 2010; Peng et al., 2005), anti-diabetic (Kojima et al., 2011; Wu et al., 2009), anti-angiogenic activities (Koo et al., 2004), et al. Since it is difficult to isolate glycoside due to its high polarity, penta-acetyl geniposide $\left((\mathrm{Ac})_{5} \mathrm{GP}\right)$, an acetylation derivative, was developed in $100 \mathrm{~g}$ scale to simplify the isolation process. The structure was identified by mass spectrophotometry and nuclear magnetic resonance. In comparison with $(\mathrm{Ac})_{5} \mathrm{GP}$ and GP, $(\mathrm{Ac})_{5} \mathrm{GP}$ exhibited the ability to activate GST and GSH-Px as GP in $\mathrm{AFB}_{1}$-treated hepatocytes and induced the activation of GST earlier than the GPtreated group. (Ac) $)_{5} \mathrm{GP}$ was shown to be more effective in inhibiting $\mathrm{AFB}_{1}$-induced unscheduled DNA synthesis in the concentration range 0.02-0.1 mM (Tseng et al., 1994).

In addition, $(\mathrm{Ac})_{5} \mathrm{GP}$ can inhibit $\mathrm{AFB}_{1}$-induced hepatic lesions, preneoplastic changes and gamma glutamyl transpeptidase ( $\gamma$-GT)-positive foci development. Although no differences were found in total number of $\gamma$-GT foci, the treatment of $(\mathrm{Ac})_{5} \mathrm{GP}$ significantly reduced the number of $\mathrm{AFB}_{1}$-induced $\gamma$ GT-positive foci with diameter larger than $0.3 \mathrm{~mm}$ (Lin et al., 2000). (Ac) $)_{5} \mathrm{GP}$, as well as GP, could be pursued as chemopreventive agents, which anti-tumor effect and mechanism have further been investigated (Peng et al., 2005, 2006).

Since $(\mathrm{Ac})_{5} \mathrm{GP}$ has a protective effect on $\mathrm{AFB}_{1}$ induced DNA damage in hepatocytes and hepatotoxicity in rats, it is interesting to further know the preventive effect of $(\mathrm{Ac})_{5} \mathrm{GP}$ on $\mathrm{D}$-GalN-induced acute liver injury in mice. In this study, (Ac) $)_{5} \mathrm{GP}$, similar to silymarin, decreased the elevated serum levels of ALT, AST and MDA and increased the reduced activities of SOD and GSH-Px in D-GalNtreated mice. These results showed a protective effect of $(\mathrm{Ac})_{5} \mathrm{GP}$ on $\mathrm{D}$-GalN-induced acute liver injury in mice.

Corresponding Author: Tianlu Shi, School of Pharmacy, Anhui Medical University, Hefei, 230032, China

This work is licensed under a Creative Commons Attribution 4.0 International License (URL: http://creativecommons.org/licenses/by/4.0/). 


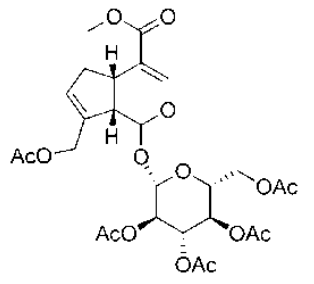

Fig. 1: Chemical structure of penta-acetyl geniposide

\section{MATERIALS AND METHODS}

Materials: GP (purity $>80 \%$ by HPLC, provided by Hefei XinFeng Co. Ltd, P. R. China) was added to a mixed solvent of pyridine and acetic anhydride (2:1), the mixed solution was stirred overnight at room temperature. The reacting product was extracted with ethyl acetate. The organic layer was washed with water, dried with anhydrous sodium sulfate, filtrated and concentrated in vacuo. The product was obtained by recrystalization with ethanol as a white powder (purity $>98 \%$ by $\mathrm{HPLC}$ ). M.p. $116-117^{\circ} \mathrm{C} ;{ }^{1} \mathrm{H}$ NMR $\left(400 \mathrm{MHz}, \mathrm{CDCl}_{3}\right) \boldsymbol{\delta}: 1.98-2.09(5 \times 3 \mathrm{H}, \mathrm{s}), 2.17(1 \mathrm{H}$, $\mathrm{m}), 2.85(2 \mathrm{H}, \mathrm{m}), 3.21(1 \mathrm{H}, \mathrm{m}), 3.73(4 \mathrm{H}, \mathrm{m}), 4.16(1 \mathrm{H}$, $\mathrm{dd}, J=2.3,12.4 \mathrm{~Hz}), 4.25(1 \mathrm{H}, \mathrm{dd}, J=4.4,12.4 \mathrm{~Hz})$, $4.70(2 \mathrm{H}, \mathrm{m}), 4.87(1 \mathrm{H}, \mathrm{d}, J=8.1 \mathrm{~Hz}), 5.01(1 \mathrm{H}, \mathrm{dd}, J$ $=8.1,9.5 \mathrm{~Hz}), 5.09(1 \mathrm{H}, \mathrm{d}, J=6.0 \mathrm{~Hz}), 5.11(1 \mathrm{H}, \mathrm{d}, J$ $=9.6 \mathrm{~Hz}), 5.23(1 \mathrm{H}, \mathrm{d}, J=9.5 \mathrm{~Hz}), 5.84(1 \mathrm{H}, \mathrm{s}), 7.42$ $(1 \mathrm{H}, \mathrm{d}, J=0.8 \mathrm{~Hz}$ ); TOF-MS $m / z: 621.1789$ (Calcd for $\mathrm{C}_{27} \mathrm{H}_{34} \mathrm{NaO}_{15}$ : 621.1790) (Fig. 1) (Lin et al., 2000).

Animals and experimental design: Six-eight-week old male Kunming mice, 20-30 g, were obtained from the Animal Department of Anhui Medical University and maintained in a controlled temperature at $23 \pm 2^{\circ} \mathrm{C}$ and $50 \pm 10 \%$ relatively humidity with a $12 \mathrm{~h}$ light/dark cycle and acclimatized for at least one week prior to use. Animals were housed in plastic cages with free access to food and water. All animals received human care in compliance with the Guidelines of the Animal Care and Use of Laboratory Animals as set by the Association of Laboratory Animal Sciences at Anhui Medical University.

Mice were randomly divided into seven groups with 10 mice per group: normal control group, model group (D-GalN group), (Ac) $)_{5} \mathrm{GP}(50,100,150 \mathrm{mg} / \mathrm{kg}$ ) groups, the silymarin group and GP group (Fu et al., 2007). Mice were administered orally by gastric gavage with different doses of $(\mathrm{Ac})_{5} \mathrm{GP}$ or silymarin or GP at a volume of $20 \mathrm{~mL} / \mathrm{kg}$ once a day for 10 days; the normal control group, D-GalN group, GP group and the silymarin group were administered with an equivalent volume of $0.3 \%$ sodium carboxymethyl cellulose saline to dissolve GP and (Ac) $)_{5} \mathrm{GP}$ in water. On day 10 , at $2 \mathrm{~h}$ after the final administered of (Ac) $)_{5} \mathrm{GP}, \mathrm{GP}$ or silymarin, the mice were intraperitoneally injected with D-GalN at the dose of $400 \mathrm{mg} / \mathrm{kg}$ as a physiological saline and the mice in the normal control group were intraperitoneally injected with an equivalent volume of physiological saline alone. At $16 \mathrm{~h}$ after the D-GalN injection, each mouse was weighed and retro-orbital bleeding to execute for blood collection, then killed by cervical dislocation. Serum was obtained from the collected blood by centrifugation immediately for measuring activities of AST and ALT and livers were weighed to calculate the liver index (liver index $=$ liver weight/body weight of mice) and take the same parts of liver $0.5 \mathrm{~g}$, to pre-cooling $0.9 \%$ saline made of $10 \%$ liver homogenates for measuring activities of SOD, GSH-Px and MDA content levels.

\section{Data collected:}

Biochemical determination: Serum levels of ALT and AST, liver homogenate SOD, GSH-Px and MDA were determined using commercial analysis kits obtained from the Jiancheng Institute of Biotechnology (Nanjing, China).

Histopathological observation: Few millimeter-thick midsection of the left lobe of liver from each animal was processed for observation by light microscopy. The process involved fixing the tissue specimen in 10\% neutral buffered formalin solution, preparing the block in paraffin, cutting into 5-6 $\mu \mathrm{m}$ thick sections and staining the sections with haematoxylin-eosin stain. Stained sections were observed under light microscopy (Olympus BX50; Olympus Japan) and later subjected to image analysis (BI 2000; TaiMeng Technology, China). The percentage area of necrosis was determined by dividing the area of necrosis by the sum of the reference area of ten low power fields.

Statistical analysis: Results were represented as means \pm S.D. and all statistical comparisons were made by one-way ANOVA test followed by Tukey post-hoc analysis and $p$-values less than or equal to 0.05 were considered to be statistically significant.

\section{RESULTS}

Effect of (Ac) $)_{5}$ GP on liver indices and serum levels of ALT and AST: The relative liver weights were significantly augmented after treatment with D-GalN alone compared to normal control group. In contrast, pretreatment with $(\mathrm{Ac})_{5} \mathrm{GP}(50,100,150 \mathrm{mg} / \mathrm{kg})$ and silymarin $(150 \mathrm{mg} / \mathrm{kg})$ significantly reduced the relative liver weights compared to model group that received DGalN alone, however, pretreatment with GP (100 $\mathrm{mg} / \mathrm{kg}$ ) had no effect on the relative liver weights.

Table 1 showed that the injection of D-GalN causes a significant elevation of serum ALT and AST levels in mice. The serum enzymes (AST and ALT), the soluble enzyme within the cytoplasm of hepatocytes, are the markers of D-GalN-induced liver damage, when liver cell was injured, it increased permeability of cell membranes, resulting in ALT and AST release into the 
Br. J. Pharmacol. Toxicol., 4(6): 256-261, 2013

Table 1: Effect of $(\mathrm{Ac})_{5} \mathrm{GP}$ on liver index $(\%)$, ALT and AST activities in serum of mice

\begin{tabular}{|c|c|c|c|c|}
\hline Group & Dose $(\mathrm{mg} / \mathrm{kg})$ & Liver index (\%) & ALT (U/L) & AST (U/L) \\
\hline Normal & - & $3.89 \pm 0.55$ & $11.71 \pm 0.87$ & $14.62 \pm 1.78$ \\
\hline Model & - & $5.35 \pm 0.30^{\# \#}$ & $25.14 \pm 2.01^{\# \#}$ & $27.68 \pm 2.79^{\# \#}$ \\
\hline GP & 100 & $4.98 \pm 0.08$ & $21.90 \pm 1.92^{* *}$ & $20.23 \pm 3.21^{* *}$ \\
\hline silymarin & 150 & $3.76 \pm 0.13^{* *}$ & $17.63 \pm 1.79^{* *}$ & $19.12 \pm 1.83^{* *}$ \\
\hline$(\mathrm{Ac})_{5} \mathrm{GP}$ & 50 & $4.27 \pm 0.21^{* *}$ & $14.85 \pm 1.38^{* *}$ & $18.29 \pm 2.51^{* *}$ \\
\hline$(\mathrm{Ac})_{5} \mathrm{GP}$ & 100 & $4.08 \pm 0.37^{* *}$ & $13.87 \pm 1.42^{* *}$ & $17.65 \pm 1.87^{* *}$ \\
\hline$(\mathrm{Ac})_{5} \mathrm{GP}$ & 150 & $3.88 \pm 0.21^{* *}$ & $12.12 \pm 0.98^{* *}$ & $16.23 \pm 1.93^{* *}$ \\
\hline
\end{tabular}

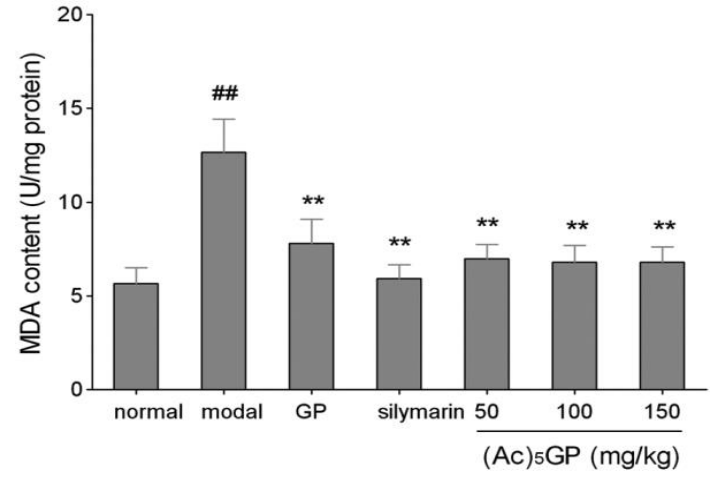

Fig. 2: Effect of (Ac) $)_{5}$ GP on MDA content in liver of mice treated with D-GalN: Data were represented as means \pm S.D. ( $n=10$ in each group) from seven separate experiment; ${ }^{\# \#} \mathrm{p}<0.01$ vs normal group; ${ }^{* * *} \mathrm{p}<0.01$ vs model group

blood, the serum levels of ALT and AST can reflect the degree of liver cell injury. Pretreatment with $(\mathrm{Ac})_{5} \mathrm{GP}$ $(50,100,150 \mathrm{mg} / \mathrm{kg}), \mathrm{GP}(100 \mathrm{mg} / \mathrm{kg})$ and silymarin $(150 \mathrm{mg} / \mathrm{kg})$ attenuated the D-GalN-induced increase in ALT and AST levels (p<0.05). (Ac) $)_{5}$ GP $(50,100,150$ $\mathrm{mg} / \mathrm{kg}$ ) reversed the above changes and the levels of serum ALT and AST showed a dose-effect relationship. The serum levels of ALT and AST were decreased in silymarin-treated group $(150 \mathrm{mg} / \mathrm{kg})(\mathrm{p}<0.05)$, while the decrease of serum level in (Ac) $)_{5}$ GP-treated groups was more significant (Table 1).

Effect of (Ac) $)_{5} G P$ on hepatic lipid peroxidation: Lipid peroxides and its metabolite MDA can damage the cell membrane structure, leading to cell swelling and necrosis, MDA content reflects the degree of peroxidative damage and cell damage. Figure 2 showed that D-GalN significantly increased MDA content in liver homogenates compared to normal control group. The abnormal change of this index in (Ac) 5 GP $(50,100$, $150 \mathrm{mg} / \mathrm{kg}$ ) groups, the silymarin group and GP group was markedly ameliorated.

Effect of (Ac) $)_{5} \mathrm{GP}$ on the levels of hepatic SOD and GSH-Px in mice: As shown in Fig. 3, antioxidant activities of $(\mathrm{Ac})_{5} \mathrm{GP}$ were estimated by examination of decrease in liver SOD and GSH-Px activity. The activities of control groups pretreatment with $(\mathrm{Ac})_{5} \mathrm{GP}$ hepatic SOD and GSH-Px activity. The activities of model group treated with D-GalN alone caused a

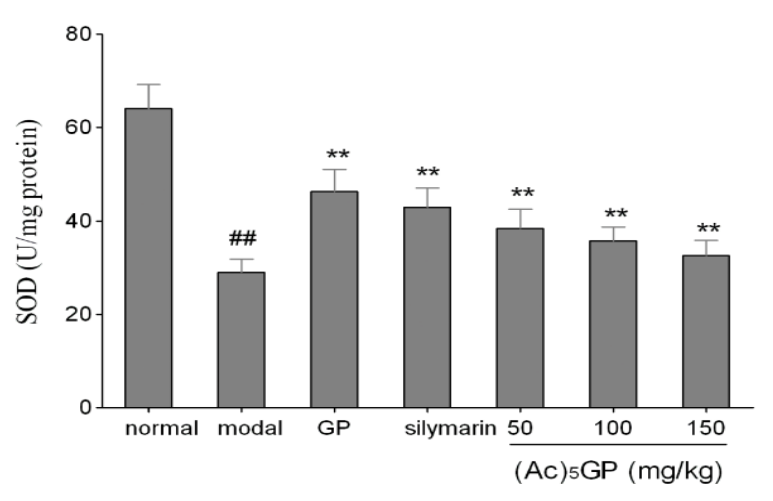

(a)

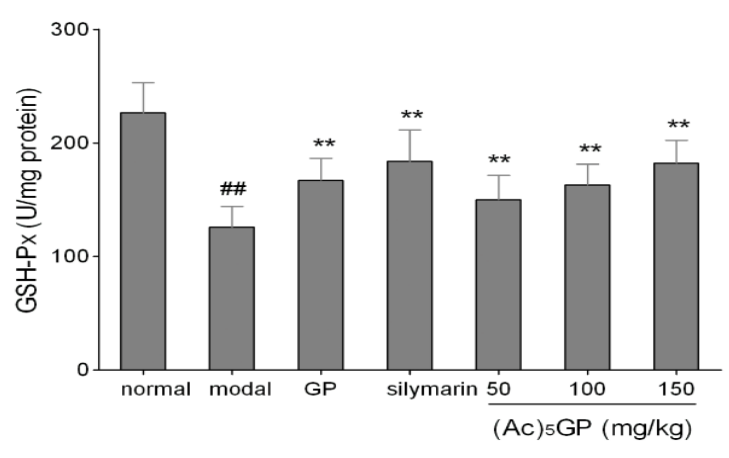

(b)

Fig. 3: Effect of (Ac) $)_{5}$ GP on the levels of the liver SOD and GSH-Px in mice Data were expressed means \pm S.D. from seven separate experiment; ${ }^{\# \#} \mathrm{p}<0.01$ vs normal group; ${ }^{* *} \mathrm{p}<0.01$ vs model group

$(50,100,150 \mathrm{mg} / \mathrm{kg}), \mathrm{GP}(100 \mathrm{mg} / \mathrm{kg})$ and silymarin $(150 \mathrm{mg} / \mathrm{kg})$ markedly increased the levels of SOD and GSH-Px.

Liver histopathology: Liver tissues were collected to assess the effect of (Ac) ${ }_{5} \mathrm{GP}$ on liver pathological changes. No histological abnormalities were observed in normal control mice. The hepatic parenchyma appeared normal and hepatocytes were arranged around the central vein (Fig. 4a). The livers of mice treated with D-GalN alone showed marked centrilobular necrosis in hepatocytes, with marked mononuclear cell infiltration (Fig. 4b). Silymarin group obviously improved the degree of damage and liver cell basic 

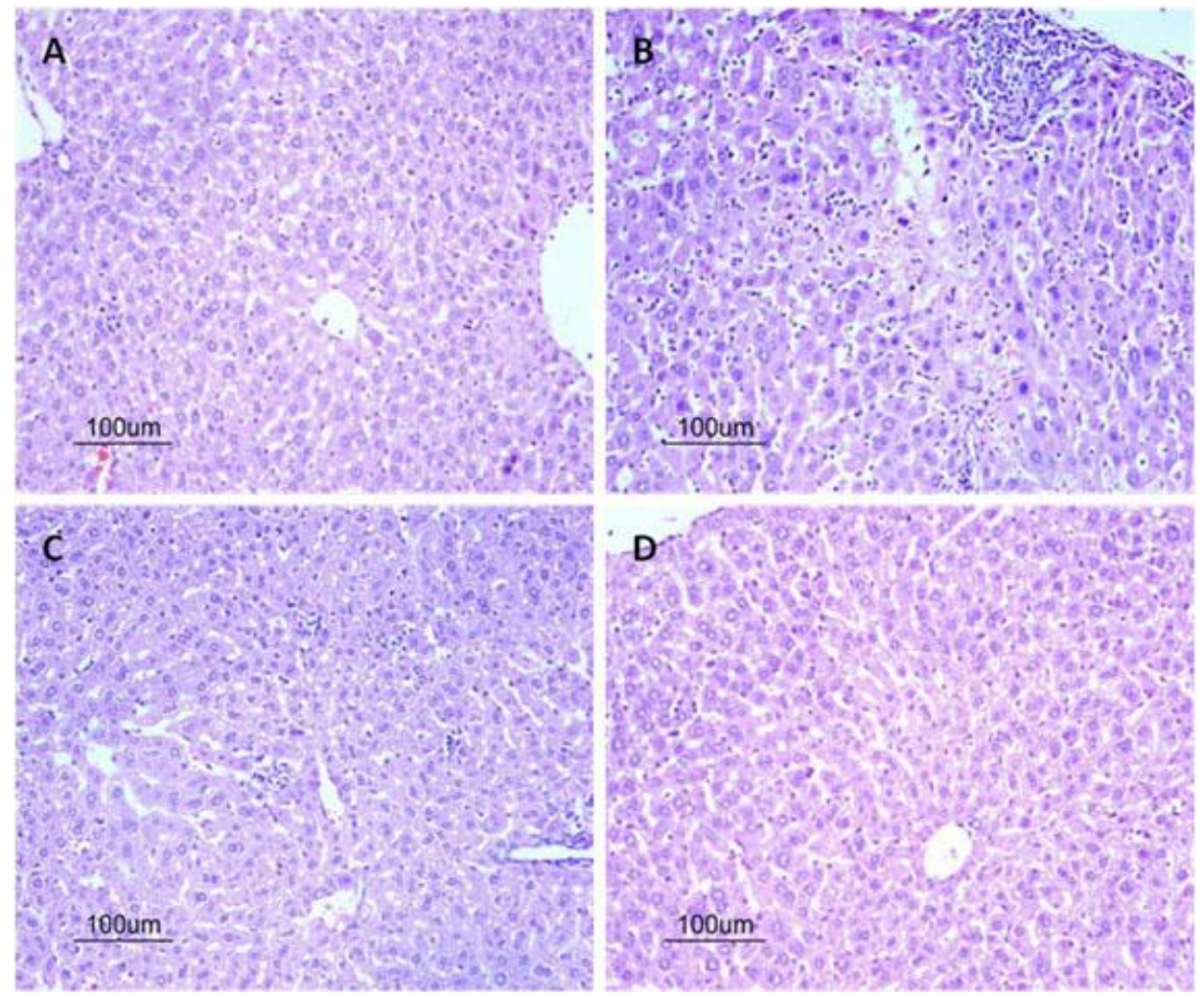

Fig. 4: Effect of $(\mathrm{Ac})_{5} \mathrm{GP}$ on the histological structure of liver: Histopathological examinations performed under a light microscope (magnification $\times 100$ ) on liver specimens obtained $16 \mathrm{~h}$ after D-GalN treatment. Figure 3A to D represent typical histological changes from normal control group, model control group, $50 \mathrm{mg} / \mathrm{kg}(\mathrm{Ac})_{5} \mathrm{GP}$ group, $100 \mathrm{mg} / \mathrm{kg} \mathrm{GP}$ group

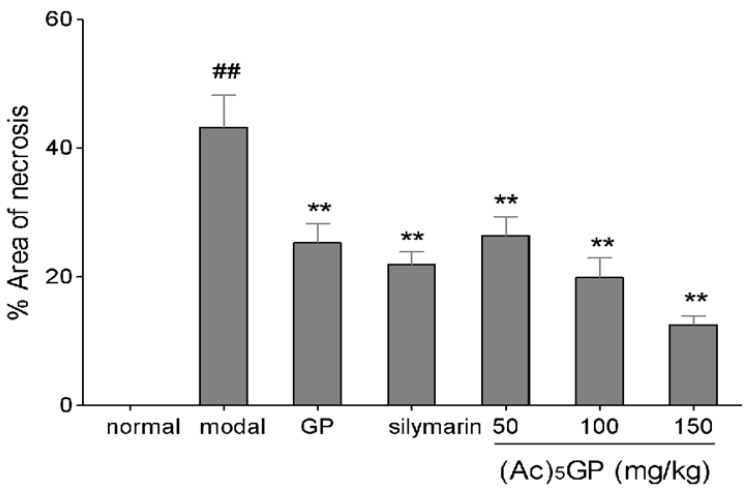

Fig. 5: The ratio of necrotic liver surface area by image analysis; Data are expressed as means \pm S.D; $n=10$ per group; ${ }^{\# \#} \mathrm{p}<0.01$ vs normal group; ${ }^{* *} \mathrm{p}<0.01$ vs model group

returned to the normal levels. The necrotic hepatocytes were characterized by cell enlargement and nuclear dissolution. The percentage area of necrosis was the highest in the D-GalN group. In the $(\mathrm{Ac})_{5} \mathrm{GP}(50$ $\mathrm{mg} / \mathrm{kg}$ ) group, the degree of necrosis was less extensive than that in livers from mice with D-GalN alone (Fig. 4c and 5). A significant difference was also observed in the GP (100 mg/kg) (Fig. 4d). Hepatocyte necrosis induced by D-GalN was alleviated by pretreatment of $(\mathrm{Ac})_{5} \mathrm{GP}$. The changes of histopathological appearance and biochemical index from D-GalNtreated mice were significant compared to normal control group. The changes from (Ac) $)_{5}$ GP-pretreated mice showed significant hepato-protective effects of (Ac) ${ }_{5} \mathrm{GP}$ against $\mathrm{D}$-GalN-induced liver injury in mice.

\section{DISCUSSION}

D-GalN, an amino sugar selectively metabolized by hepatocytes, has been found to induce liver damage which closely resembles human viral hepatitis (Decker and Keppler, 1972). Oxygen-derived free radicals released from activated hepatic-macrophages are the primary cause of D-GalN-induced liver damage (Shiratori et al., 1988). And increased production of reactive oxygen species (ROS) has been observed in primary culture of rat hepatocytes damage induced by GalN (Quintero et al., 2002). The serum enzymes (AST and ALT) are the markers of D-GalN-induced liver damage. (Ac) $)_{5} \mathrm{GP}(50,100,150 \mathrm{mg} / \mathrm{kg})$ reversed these changes and the serum levels of ALT and AST showed a dose-effect relationship. These evidences suggested that the hepato-protective effects of (Ac) $)_{5} \mathrm{GP}$ might be mediated through reducing ROS. 
SOD is the antioxidant enzymes of the animal body, its can remove free radicals and prevent free radical damage to the cell structure, the size of its vitality reflects the antioxidant, free radical scavenging capacity. GSH-Px, along with SOD, is one of the body's endogenous antioxidants and is well-known to protect liver cells against oxidative damage through chemical or enzymatic reactions.

MDA, a secondary product of lipid peroxidation, is a useful indicator of tissue damage involving a series of chain reactions (Ohkawa et al., 1979). And a reduction in the activity of SOD is associated with the accumulation of highly reactive free radicals, leading to deleterious effects such as loss of integrity and function of cell membranes (Jayakumar et al., 2006). Reducing GSH constitutes the first line of defense against free radicals (Raja et al., 2006). GP and (Ac) $)_{5} \mathrm{GP}$ at all tested doses prevented elevation of liver MDA content, reduction of liver SOD activity and increase of GSH content resulted from mice liver intoxication with $D$ GalN. These observations further suggested that GP and (Ac) ${ }_{5} \mathrm{GP}$ had free radical scavenging activities.

Silymarin is used as standard hepatoprotective agent due to its excellent hepatoprotective activity in xenobiotic intoxication and fungal intoxication (Dixit et al., 2007). (Ac) ${ }_{5} \mathrm{GP}$, the same as silymarin, reversed the elevated serum levels of ALT, AST, MDA and the decrease of SOD and GSH-Px activity in D-GalNtreated mice. This supported that $(\mathrm{Ac})_{5} \mathrm{GP}$ can be developed as a hepatoprotective agent.

Furthermore, compared to GP group $(100 \mathrm{mg} / \mathrm{kg})$, (Ac) $)_{5} \mathrm{GP}(100 \mathrm{mg} / \mathrm{kg})$ was shown to more decrease the elevated serum levels of ALT, AST and MDA and more increase the reduced activity of SOD in D-GalNtreated mice. (Ac) $)_{5} \mathrm{GP}$ induced activation of GST earlier than the GP-treated group in AFB1-treated hepatocytes, which may faster inhibit cytochrome P450 monooxygenase (Tseng et al., 1994). These evidences indicated that $(\mathrm{Ac})_{5} \mathrm{GP}$ may be a more potential hepatoprotective agent than GP.

\section{CONCLUSION}

In conclusion, the present study reveals that (Ac) $)_{5}$ GP shows a good hepato-protective effect on DGalN-induced liver injury and this protection may be mediated through an antioxidative effect. (Ac) 5 GP may be more effective than GP in reducing D-GalN-induced hepatotoxicity in mice. From histopathological study, it also reveals that $(\mathrm{Ac})_{5} \mathrm{GP}$ normalized the livers. In vivo evidence showed no toxic effects with (Ac) $)_{5} \mathrm{GP}$ and GP (Yamano et al., 1990). Therefore, this easily prepared (Ac) $)_{5}$ GP can be developed as a more potential hepatoprotective agent, which is necessary to further study the hepato-protective mechanisms.

\section{ACKNOWLEDGMENT}

The study was financially supported by National Natural Science Foundation of China (No. 20802003),
TCM scientific research projects of Anhui Province Health Department 2012 (No. 2012zy46).

\section{REFERENCES}

Cao, H.L., Q. Feng, W. Xu, X.R. Li, Z. Kang, Y.Q. Ren and L.F. Du, 2010. Genipin induced apoptosis associated with activation of the c-Jun NH2terminal Kinase and p53 protein in HeLa cells. Biol. Pharm. Bull., 33(8): 1343-1348.

Decker, K. and D. Keppler, 1972. Progress in Liver Disease. In: Popper. H. and F. Schaffner, (Eds.), Galactosamine Induced Liver Injury. Grune and Stratton, New York, pp: 183-199.

Dixit, N., S. Baboota, K. Kohli, S. Ahmad and J. Ali, 2007. Silymarin: A review of pharmacological aspects and bioavailability enhancement approaches. Indian J. Pharmacol., 39(4): 172-179.

Fu, T., Q. Pu and J. Tan, 2007. The gardenia geniposidic protective effect of ethanol induced acute liver injury. Pharmacol. Clin. Chin. Mater. Med., 23(3): 25-27.

Jayakumar, T., E. Ramesh and P. Geraldine, 2006. Antioxidant activity of the oyster mushroom, Pleurotus ostreatus, on $\mathrm{CCl}_{4}$-induced liver injury in rats. Food Chem. Toxicol., 44(12): 1989-1996.

Kojima, K., T. Shimada, Y. Nagareda, M. Watanabe, J. Ishizaki, Y. Sai, K. Miyamoto and M. Aburada, 2011. Preventive effect of geniposide on metabolic disease status in spontaneously obese type 2 diabetic mice and free fatty acid-treated HepG2 cells. Biol. Pharm. Bull., 34(10): 1613-1618.

Koo, H.J., S. Lee, K.H. Shin, B.C. Kim, C.J. Lim and E.H. Park, 2004. Geniposide, an anti-angiogenic compound from the fruits of Gardenia jasminoides. Planta Med., 70(5): 467-469.

Lin, Y.L., J.D. Hsu, F.P. Chou, M.J. Lee, S.J. Shiow and C.J. Wang, 2000. Suppressive effect of pentaacetyl geniposide on the development of $\gamma$ glutamyl transpeptidase foci-induced by aflatoxin $\mathrm{B}_{1}$ in rats. Chem. Biol. Interact., 128(2): 115-126.

Liu, H.T., J.L. He, W.M. Li, Z. Yang, Y.X. Wang, J. Yin, Y.G. Du and C. Yu, 2010. Geniposide inhibits interleukin-6 and interleukin-8 production in lipopolysaccharide-induced human umbilical vein endothelial cells by blocking p38 and $\mathrm{ERK}_{1 / 2}$ signaling pathways. Inflamm. Res., 59(6): 451-461.

Liu, J.H., F. Yin, L.X. Guo, X.H. Deng and Y.H. Hu, 2009. Neuroprotection of geniposide against hydrogen peroxide induced PC12 cells injury: Involvement of PI3 kinase signal pathway. Acta Pharmacol. Sin., 30:159-165.

Liu, J.H., F. Yin, X.X. Zheng, J.J. Jing and Y.H. Hu, 2007. Geniposide, a novel agonist for GLP-1 receptor, prevents $\mathrm{PC} 12$ cells from oxidative damage via MAP kinase pathway. Neurochem. Int., 51(6-7): 361-369. 
Ma, T.T., C. Huang, G.J. Zong, D.J. Zha, X.M. Meng, J. Li and W.J. Tang, 2011. Hepatoprotective effects of geniposide in a rat model of nonalcoholic steatohepatitis. J. Pharm. Pharmacol., 63: 587-593.

Ohkawa, H., N. Ohishi and K. Yagi, 1979. Assay of lipid peroxides in animal tissue by thiobarbituric acid reaction. Anal. Biochem., 95(2): 351-358.

Peng, C.H., C.N. Huang and C.J. Wang, 2005. The antitumor effect and mechanisms of action of pentaacetyl geniposide. Curr. Cancer Drug Tar., 5: 299-305.

Peng, C.H., C.N. Huang, S.P. Hsu and C.J. Wang, 2006. Penta-acetyl geniposide induce apoptosis in C6 glioma cells by modulating the activation of neutral sphingomyelinase-induced p75 nerve growth factor receptor and protein kinase $\mathrm{C} \delta$ pathway. Mol. Pharmacol., 70(3): 997-1004.

Peng, C.H., T.H. Tseng, J.Y. Liu, Y.H. Hsieh, C.N. Huang, S.P. Hsu and C.J. Wang, 2004. Pentaacetyl geniposide-induced C6 glioma cell apoptosis was associated with the activation of protein kinase C $\delta$. Chem. Biol. Interact., 147: 287-296.

Quintero, A., C.A. Pedraza, E. Siendones, E.A. Kamal, A. Colell, C. Garcĺa-Ruiz, J.L. Montero, M.M. Dela, J.C. Fernández-Checa, G. MiŇo, J. Muntané, E.A. Kamal and A. Colell, 2002. PGE1 protection against apoptosis induced by $\mathrm{D}$-galactosamine is not related to the modulation of intracellular free radical production in primary culture of rat hepatocytes. Free Radical Res., 36(3): 345-355.

Raja, S., K.F. Ahamed, V. Kumar, K. Mukherjee, A. Bandyopadhyay and P.K. Mukherjee, 2006. Antioxidant effect of Cytisus scoparius against carbon tetrachloride treated liver injury in rats. J. Ethnopharmacol., 109(1): 41-47.
Shiratori, Y., T. Kawase, S. Shiina, K. Okano, T. Sugimoto, H. Teraoka, S. Matano, K. Matsumoto and K. Kamii, 1988. Modulation of hepatotoxicity by macrophages in the liver. Hepatology, 8(4): 815-821.

Tseng, T.H., C.Y. Chu and C.J. Wang, 1994. Comparison of geniposide and its acetylated derivative for the inhibition of aflatoxin B1induced DNA repair synthesis in rat primary hepatocyte. Oncol. Rep., 1: 165-168.

Wu, S.Y., G.F. Wang, Z.Q. Liu, J.J. Rao, L. Lü, W. Xu, S.G. Wu and J.J. Zhang, 2009. Effect of geniposide, a hypoglycemic glucoside, on hepatic regulating enzymes in diabetic mice induced by a high-fat diet and streptozotocin. Acta Pharmacol. Sin., 30: 202-208.

Yamano, T., Y. Tsujimoto, T. Noda, M. Shimizu, M. Ohmori, S. Morita and A. Yamada, 1990. Hepatotoxicity of geniposide in rats. Food Chem. Toxicol., 28: 515-519.

Yang, X.F., Q.R. Cai, J.P. He, X. Chu, M.M. Wei, X.R. Feng, X.X. Xie, M.X. Huo, J. Liu, J.Y. Wei, X.X. Ci, H.Y. Li, Y.H. Deng, L.X. Jiang and X.M. Deng, 2012. Geniposide, an iridoid glucoside derived from Gardenia jasminoides, protects against lip polysaccharide-induced acute lung injury in mice. Planta Med., 78(6): 557-564. 